\title{
HADIS DAN SUNNAH NABI DALAM PERSPEKTIF JOSEPH SCHACHT
}

\author{
Latifah Anwar \\ latifah.anwar18@gmail.com. \\ Ilmu Hadis, Fakultas Ushuluddin dan Filsafat, Universitas Islam Negeri Sunan Ampel \\ Surabaya, Indonesia
}

\begin{abstract}
Research about Hadith authenticity becomes Orientalist's preferred study. Joseph Schacht, one of orientalist researcher had researched and criticized Hadith authenticity. Schacht assumed that Sunnah was not formerly from Prophet Muhammad, but it was the continuity of Arabian traditions which were revised and done continuously by Moslem and hold up to Prophet Muhammad. Schacht assumed that Prophet's sunnah had not been established surely to Hadith. Schacht's research was started by studying Islam law establishment process. Then, he concluded that Islam law had not been existed until Al-Sya'bi era $(110 \mathrm{H})$. At Tabi'in era, there was Hadith which was not available at the previous one. Hadith in Tabi'in's era was considered complete than companions' version. Hadith at the next version was spread out by falsification. Schacht mentioned that Isnad was part of arbitrariness in Prophet Muhammad Hadith since it was developed by different groups who expected to relate it to the previous one. Sanad reconstruction formation based on Schacht's opinion, namely by doing backward design, known as Projecting Back theory. Sanad Hadith common indicators showed that the longer period of people far from Prophet Muhammad era, the more people narrated Hadith. Schacht mentioned that the practice of sanad Hadith was started from the simple way, then it was developed and formed the perfect sanad at the second period of third century of Hijriyah.
\end{abstract}

Keywords: Hadith; Joseph Schacht: Prophet; Sunnah

\begin{abstract}
Abstrak
Studi tentang otentitas hadis merupakan wilayah penelitian yang cukup diminati oleh orientalis. Joseph Schacht, salah satu peneliti dari kalangan orietalis ternyata telah banyak meneliti dan mengkritik otentitas hadis. Schacht mengangap Sunnah bukan berasal dari Nabi, tetapi hanya kelanjutan dari tradisi bangsa Arab yang direvisi dan diteruskan oleh Islam kemudian disandarkan kepada Nabi. Menurut Schacht, Sunnah Nabi belum diwujudkan secara khusus kepada hadis-hadis Nabi. Studi Schacht diawali dengan meneliti proses kemunculan hukum Islam, kemudian dari hasil penelitiannya Schacht menyimpulkan bahwa hukum Islam belum ada sampai pada masa al-Sya 'bi $($ w.110 H). Pada periode Tabi in terdapat hadis yang tidak terdapat dalam periode sebelumnya. Hadis dalam versi Tabi in dianggap lebih lengkap daripada hadis dalam versi sahabat. Sedangkan hadis pada versi selanjutnya telah berkembang dengan cara pemalsuan. Schacht mengangap Isnad adalah bagian dari tindakan sewenang-wenangan dalam hadis nabi Saw. karena Hadis itu sendiri dikembangkan oleh kelompokkelompok yang berbeda-beda yang ingin mengaitkan teorinya kepada tokoh-tokoh terdahulu. Rekonstruksi terbentuknya sanad menurut Schacht, yaitu dengan melakukan
\end{abstract}


rancang bangun ke belakang yang dikenal dengan teori Projecting Back. Gejala umum yang terdapat dalam sanad hadis yaitu semakin jauh orang-orang dari masa Nabi Saw., semakin bertambah pula jumlah orang-orang yang meriwayatkan hadis Nabi Saw. Menurut Schacht, pemakaian sanad hadis dimulai dalam bentuk yang sangat sederhana, kemudian berkembang dan membentuk sanad yang sempurna pada paruh kedua abad ketiga Hijriyah.

Kata Kunci: Hadis; Joseph Schacht; Nabi; Sunnah

\section{A. Pendahuluan}

Pemikiran Schacht tentang hadis mulai terkuak ke publik saat ia menyampaikan orasi ilmiah dengan judul "A Revolution of Islamic Traditions" pada Kongres Orientalis ke-21 di Paris pada bulan Juli $1948 .^{1}$

Adalah Schacht, di antara para sarjana Barat, yang meruntuhkan pemahaman tradisional tentang hukum Islam. Berbeda dengan pemahaman tradisional ini, kajian Schacht tentang persoalan itu tidak bersifat teologis maupun yuristik, tetapi lebih bersifat historis dan sosiologis. Ia menyajikan hukum Islam bukan sebagai seperangkat norma yang diwahyukan, tetapi sebagai historis yang berhubungan erat dengan realitas sosial. Tidak mengherankan sama sekali bahwa kesimpulan Schacht masih mengejutkan sebagian besar orang muslim sejak kesimpulan itu diusulkan pertama kali, karena Schacht menunjukkan bahwa sebagian besar hukum Islam, temasuk sumber-sumbernya, merupakan akibat dari sebuah proses perkembangan historis. ${ }^{2}$

Schacht telah mempelajari kitab al-Muwathta' karya Imam Malik, kitab alMuwathta' karya Imam Muhammad al-Syaibani, dan kitab al-Umm karya Imam alSyafi'i. Kitab-kitab ini sebenarnya lebih tepat disebut sebagai kitab-kitab fiqih daripada kitab-kitab hadis. Namun demikian, Schacht telah menggeneralisasikan hasil kajiannya terhadap kitab-kitab tersebut, sekaligus menerapkannya untuk seluruh kitab-kitab hadis.

\footnotetext{
${ }^{1}$ Cahya Edi Setyawan, "Studi Hadits: Analisis Terhadap Pemikiran Schacht dan A'zami”, Jurnal Kajian Islam Interdisipliner, Vol.1, No. 2 (Desember, 2016), 260

${ }^{2}$ Akhmad Minhaji, Kontroversi Pembentukan Hukum Islam, terj. Ali Masrus (Yogyakarta: UII Yogyakarta, 2001), 16
} 
Seolah-olah tidak ada kitab yang khusus mengenai hadis, dan seolah-olah tidak ada perbedaan antara watak kitab fiqih dan kitab hadis. ${ }^{3}$

Hadis Nabi adalah suatu materi yang berdiri sendiri, bahkan ia mencakup ilmuilmu yang lain. Oleh karena itu, ditinjau dari segi ilmiah adalah suatu kesalahan yang mendasar apabila meneliti hadis-hadis yang terdapat dalam kitab-kitab fiqih. Karenanya, semua penelitian hadis serta sanad di luar sumber yang asli, hasilnya akan meleset dari kebenaran. Sebab, hal itu tidak akan membawa kepada kesimpulan yang tepat, tetapi justru akan berlawanan dengan kenyataan yang ada. ${ }^{4}$

\section{B. Pandangan Joseph Schacht tentang Pengertian Hadis dan Sunnah Nabi}

Sunnah Nabi merupakan wilayah penting dalam penelitian Schacht walaupun setelah diakui bahwa, Goldziher adalah pelopor kajian kritis terhadap hadis. Namun demikian, perkembangan sistematis dari gagasannya (Goldziher), formulasi rinci mengenai kriteria untuk mengevaluasi hadis, dan penerapannya tehadap sejumlah besar bahan-bahan dalam sumber-sumber Arab asli, merupakan karya Joseph Schacht. Schacht sendiri mengakui bahwa kesimpulannya hanya menguatkan dan mengebolarasi teori besar yang telah diajukan oleh para pendahulunya, Goldziher. ${ }^{5}$

Joseph Schacht bersama Ignaz Goldziher barangkali dianggap dua di antara sekian banyak orientalis yang sering diungkap dalam perdebatan hadis dan Sunnah. Kiprahnya dalam riset-riset hadis telah memposisikan Schacht sebagai orientalis yang mendapat serangan para ahli hadis Muslim. ${ }^{6}$

Dalam kajian Ilmu Hadis, Ulama hadis sering mengidentikkan kata hadis dengan kata Sunnah, khabar, dan atsar. Kata hadis lebih sering digunakan baik di kalangan ulama maupun umat Islam daripada kata Sunnah, khabar, dan atsar. Secara bahasa, kata hadis (al-hadits) berarti baru, yaitu الجديد من الأثياء (sesuatu yang baru), bentuk jamak

\footnotetext{
${ }^{3}$ M.M. Azami, Hadis Nabawi dan Sejarah Kodifikasinya, terj. Ali Mustafa Yaqub (Jakarta: Pustaka Firdaus, 2014), 538

${ }^{4}$ Ibid., 547

${ }^{5}$ Minhaji, Kontroversi Pembentukan..., 17

${ }^{6}$ Ucin Muksin, "al-Hadits dalam Pandangan Orientalis (Joseph Schacht)", Ilmu Dakwah: Academic Journal for Homiletic Studies, Vol. 4, No.11 (Januari-Juni, 2008), 116
} 
hadis dengan makna ini hidats, hudatsa, dan huduts, dan lawan katanya qadim (sesuatu yang lama). ${ }^{7}$

Menurut Taqi al-Din ibn Taymiyyah, sebagaimana dikutip oleh al-Qasimi, hadis secara mutlak berkenaan dengan sesuatu yang diberitakan dari Rasulullah setelah diutus menjadi Nabi, baik perkataan, perbuatan maupun ketetapannya. Karena itu, apa yang dikatakan oleh Nabi Muhammad meskipun hanya satu berita maka wajib dipercaya, dan jika mengandung hukum wajib, haram, atau mubah maka wajib diikuti. ${ }^{8}$

Hadis pada umumnya digunakan untuk istilah segala sesuatu yang diriwayatkan dari Rasulullah setelah diutus menjadi Nabi. Sebagian ulama berpendapat bahwa hadis hanya terbatas pada ucapan dan perbuatan Nabi saja, sedangkan persetujuan dan sifatsifatnya tidak termasuk hadis karena keduanya merupakan ucapan dan perbuatan sahabat. Selain itu, hadis juga digunakan untuk sesuatu yang disandarkan kepada Allah yang dikenal dengan hadis qudsi, yaitu hadis yang disandarkan oleh Nabi kepada Allah. Disebut hadis karena berasal dari Rasulullah dan dikatakan qudsi sebab disandarkan kepada Allah. Di sini terlihat pula perbedaan antara hadis dan Sunnah, sebab tidak pernah disebut Sunnah Qudsiyyah. ${ }^{9}$

Istilah hadis sering disejajarkan dengan istilah Sunnah, walaupun kedua istilah itu tidak selalu identik karena keduanya juga memiliki perbedaan. Di kalangan ulama hadis, hadis merupakan sinonim Sunnah, namun hadis pada umumnya digunakan untuk istilah segala sesuatu yang diriwayatkan dari Rasulullah setelah diutus menjadi Nabi. Sebagian ulama berpendapat bahwa hadis hanya terbatas ucapan dan perbuatan Nabi saja, sedang persetujuan dan sifat-sifatnya tidak termasuk hadis karena keduanya merupakan ucapan dan perbuatan sahabat. Berbeda dengan ulama hadis, ulama Ushul al-Fiqh berpendapat bahwa, hadis lebih khusus daripada Sunnah sebab hadis menurut mereka adalah Sunnah Qawliyyah. ${ }^{10}$

\footnotetext{
${ }^{7}$ Idri, Hadis dan Orientalis Perspektif Ulama Hadis dan Para Orientalis tentang Hadis (Depok: Kencana, 2017), 89

${ }^{8}$ Ibid., 91

${ }^{9}$ Ibid., 92-93

${ }^{10}$ Idri, Studi Hadis (Jakarta: Kencana, 2010), 311
} 
Secara bahasa, Sunnah berarti a way, course, rule, mode, or manner of acting or conduct of life (jalan, arah jalan, aturan, cara berbuat atau tingkah laku keidupan). Dalam al-Qur'an, kata Sunnah dan bentuk jamaknya sunan diulang sebanyak lima belas kali yang mempunyai arti pelaksanaan course of rule (arah suatu aturan), mode of life (cara hidup), dan line of conduct (garis-garis tingkah laku). Menurut pengertian etimologis ini, Sunnah juga berarti jalan hidup yang baik ataupun yang buruk. ${ }^{11}$

Makna Sunnah menurut ulama hadis sangat luas mencakup segala aspek kehidupan Nabi semenjak lahir hingga wafat, setelah diangkat menjadi Nabi ataupun sebelumnya, dan menunjukkan hukum syar' $i$ ataupun tidak. Nabi dipandang secara totalitas dari sisi sebagai pemimpin, pemberi petunjuk, pemberi nasihat, suri teladan, dan panutan baik setelah mendapat wahyu dari Allah yang dimulai dengan surah al'Alaq ayat 1-5 maupun sebelumnya ketika belum diangkat menjadi nabi dan rasul. ${ }^{12}$

Dalam pandangan orientalis, hadis juga dipandang berbeda dengan Sunnah. perbedaan ini antara lain terlihat pada pendapat Ignaz Goldziher yang menyatakan bahwa hadis bermakna suatu disiplin ilmu yang bersifat teoritis, sedang Sunnah berisi aturan-aturan praktis. Menurutnya, kebiasaan-kebiasaan yang muncul dalam ibadah dan hukum yang diakui sebagai tata cara kaum muslimin periode awal yang dipandang otoritatif dan telah dipraktikkan dinamakan Sunnah, sedangkan pernyataan tentang tata cara itu disebut hadis. ${ }^{13}$

Ignaz Goldziher menyatakan bahwa perbedaan antara Sunnah dan Hadis bukan saja dari maknanya, tetapi melebar pada adanya pertentangan dalam materi hadis dan Sunnah. Menurutnya, hadis bercirikan berita lisan yang dinilai bersumber dari Nabi, sedangkan Sunnah berdasar kebiasaan yang lazim digunakan di kalangan umat Islam awal yang menunjuk pada permasalahan hukum dan keagamaan, baik ada atau tidak ada berita lisan tentang kebiasaan itu. Suatu kaidah yang terkandung di dalam hadis biasanya dipandang sebagai Sunnah, tetapi tidak berarti Sunnah harus mempunyai hadis yang relevan dan mengukuhkannya. Lebih lanjut Goldziher menyatakan bahwa Sunnah sebenarnya hanyalah sebuah revisi atas adat istiadat bangasa Arab yang sudah ada.

\footnotetext{
${ }^{11}$ Idri, Hadis dan Orientalis, 93

${ }^{12}$ Ibid., 94

${ }^{13}$ Ibid., 98
} 
Dengan demikian, menurut Goldziher Sunnah bukanlah suatu yang berasal dari Nabi tetapi merupakan kebiasaan yang sudah berkembang di kalangan bangsa Arab yang direvisi dan kemudian dilanjutkan oleh umat Islam sebagai suatu tradisi.

Pendapat senada dikemukakan oleh Joseph Schacht bahwa, Sunnah merupakan konsep bahasa Arab kuno yang berlaku kembali sabagai salah satu pusat pemikiran Islam. Menurutnya, Sunnah lebih merupakan tradisi Arab kuno yang kembali mengemuka dalam ajaran Islam. ${ }^{14}$

Dalam konteks ini, Fazlur Rahman menyimpulkan makna Sunnah menurut Schacht sebagai tradisi dari Nabi yang tidak ada sama sekali sampai abad kedua Hijriyah. Kebiasaan sebelum waktu itu tidak dipandang sebagai Sunnah Nabi, tetapi sebagai Sebagai sunnah masyarakat karena sunnah tersebut adalah hasil penalaran bebas orang-orang. Dapat dikatakan bahwa pandangan Goldziher dan Schacht tentang Sunnah realatif sama. Keduanya menganggap Sunnah bukan sesuatu yang berasal dari Nabi, tetapi hanya kelanjutan dari tradisi bangsa Arab Jahiliyah yang kemudian direvisi dan diteruskan oleh Islam serta kemudian disandarkan kepada Nabi.

Pandangan para orientalis termasuk Goldziher dan Schacht bertentangan secara diametral dengan pandangan para ulama hadis dan ushul fiqh. Karena ulama hadis dan ulama ushul fiqh memahami hadis dan Sunnah bersumber atau berasal dari Nabi. ${ }^{15}$

Dapat dikatakan bahwa, pandangan Goldziher dan Schacht tentang Sunnah relatif sama. Keduanya menganggap Sunnah bukan sesuatu yang berasal dari Nabi, tetapi hanya kelanjutan dari tradisi bangsa Arab yang kemudian direvisi dan diteruskan oleh Islam serta kemudian disandarkan kepada Nabi. ${ }^{16}$

Sunnah dalam pandangan Schacht bermakna tidak lebih dari sebuah kebiasaan yang dapat dijadikan teladan, sebuah pandangan hidup. Akan menjadi jelas bahwa ide tentang Sunnah sebagai bimbingan prinsipil bagi masyarakat juga diambil alih dan diadopsi oleh orang-orang muslim setelah wafatnya Muhammad, khususnya selama era al-Khulafa' al-Rasyidun. hal ini didukung oleh kenyataan, misalnya, bahwa Khalifah

\footnotetext{
${ }^{14}$ Idri, Studi Hadis..., 312-313

${ }^{15}$ Idri, Hadis dan Orientalis..., 103-104

${ }^{16}$ Ibid.
} 
kedua, 'Umar ibn al-Khaththab telah mengirim surat kepada Abu Musa al-Asy'ari (seorang qadhi Basrah) yang berisi instruksi untuk memakai Sunnah yang berlaku sebagai salah satu dari sumber-sumber penting yang berkenaan dengan persoalan hukum. ${ }^{17}$

Schacht menegaskan kembali bahwa istilah Sunnah Nabi belum diwujudkan secara khusus kepada hadis-hadis dari Nabi. (Menurutnya) Perkembangan doktrin terus menerus dalam aliran klasik dipercepat oleh gerakan para ahli hadis. Menurut para ahli hadis, hadis-hadis formal (Hadits, bentuk jamaknya Ahadits) yang berasal dari Nabi menggantikan tradisi yang hidup dari aliran itu. Sebagai akibatnya, terdapat sejumlah hadis yang berkembang yang diklaim menjadi laporan-laporan dari saksi-saksi yang mendengar atau melihat perkataan-perkataan atau perbuatan-perbuatan Nabi, yang diriwayatakan secara lisan dengan rangkaian (isnad) orang-orang terpercaya yang tidak terputus. Analisis ini membawa Schacht kepada kesimpulan kontroversial yang meruntuhkan pemahaman muslim tradisional. ${ }^{18}$ Prof. Schacht terpengaruh untuk menilai watak umum hadis yang lebih sistematik melalui pengkajian keagamaannya dalam hukum Islam, dan perkembangan teori hukum dalam Islam. ${ }^{19}$

Selama kehidupan Muhammad, ia (Schacht) beralasan, Sunnah yang ada pada masyarakat dimasukkan sebagai salah satu dari sumber-sumber penting untuk memecahkan berbagai persoalan masyarakat muslim dan menjadi salah satu konsep pokok hukum Islam. Sunnah ini selama periode al-Khulafa' al-Rasyidun bercampur dengan Sunnah wilayah-wilayah yang ditaklukkan di luar Jazirah Arab. ${ }^{20}$

Tahapan selanjutnya dari perkembangan itu terjadi selama periode Umayyah. Khalifah memilih Qudhah (bentuk jamak dari kata qadhi, seorang hakim) di masingmasing propinsi untuk memecahkan barbagai permaslahan hukum. Hukum adat (Sunnah) masing-masing propinsi dan praktek populer serta aturan-aturan administrasi rezim Umayyah, yang ditafsirkan oleh para Qudhah melalui ra'yu mereka, dianggap sebagai sumber utama yang digunakan untuk menyelesaikan permasalahan-

\footnotetext{
${ }^{17}$ Minhaji, Kontroversi Pembentukan..., 21

${ }^{18}$ Ibid., 22

${ }^{19}$ Fazlur Rahman, Islam, terj. Shonhadji (Jakarta: Bumi Aksara, 1992), 72

${ }^{20}$ Minhaji, Kontroversi Pembentukan..., 25
} 
permasalahan hukum. Qudhah ini adalah pegawai-pegawai administrasi rezim Umayyah dan keputusan-keputusan mereka meletakkan pondasi dasar bagi apa yang kemudian menjadi hukum Islam. Di sini upaya teorisasi, sistemisasi, dan islamisasi pertama berawal secara serius. Pada beberapa dekade pertama abad kedua, Qudhah ini menjadi lebih spesialis, lebih tertarik dengan agama, dan dengan memakai pemikiran pribadi mereka. Mereka memperhatikkan perluasan pandangan hidup Islam yang mencakup sistem hukum Islam. Sebagai akibatnya, Schacht menjelaskan, praktek populer dan administrasi Umayyah periode terakhir ditransformasikan ke dalam hukum Islam. Pada tahap perkembangan berikutnya, bersama dengan para spesialis agama yang lain, mereka memunculkan apa yang disebut madhahib yang benar-benar berbeda dengan pembagian geografis mereka. Aliran yang paling penting adalah aliran-aliran Kufah dan Basrah di Irak, aliran Makkah dan Madinah di hijaz, serta aliran Syiria. ${ }^{21}$

Klaim tersebut tidak bisa diterima oleh ulama hadis karena Sunnah dan hadis secara teoritis dan praktis telah terbukti ada sejak masa Rasulullah. ${ }^{22}$ Secara praktis, petunjuk dan teladan Rasulullah selalu menjadi rujukan para sahabat dan generasigenerasi sesudahnya dalam kehidupan sehari-hari. Oleh karena itu, Sunnah berkaitan dengan segala yang bersangkut paut dengan Nabi dan sinonim dengan hadis. Sunnah dan hadis memang benar-benar berasal dari Rasulullah bukan dari luar Islam, tidak dikutip dari Perjanjian Lama dan Perjanjian Baru, perkataan pendeta Yahudi, ataupun doktrin-doktrin ahli filsafat Yunani, Persia, India, dan lain-lain. Hal ini dapat dilihat pada kandungan Hadis dan Sunnah yang tidak sama dengan kandungan berbagai kitab dan doktrin-doktrin itu. Hadis dan Sunnah hanya sejalan dengan ajaran al-Qur'an dan bertentangan dengan ajaran-ajaran di luar itu. Rasulullah pernah membolehkan menceritakan hal-hal yang berasal dari Bani Israil, tetapi tidak berarti bahwa kandungan hadis dan Sunnah diambil dari berita-berita Bani Israil. ${ }^{23}$

Seandainya hadis dan Sunnah diambil dari tradisi Arab jahiliyah, Bani Israil, atau doktrin para ahli filsafat, niscaya merupakan kompilasi berbagai ajaran, doktrin dan konsep yang sangat tidak mungkin dilakukan. Tradisi Arab paganisme, ajaran kitab

\footnotetext{
${ }^{21}$ Ibid., 25-26

${ }^{22}$ Idri, Hadis dan Orientalis..., 104

${ }^{23}$ Ibid., 103-104
} 
Perjanjian Lama dan Perjanjian Baru serta konsep filsafat Yunani, Persia, dan India sangat bertentangan satu dengan yang lain, dan di dalamnya terkandung faham animisme, dinamisme, trinitas, bahkan ateisme yang jelas-jelas tidak pernah diajarkan dalam hadis dan Sunnah. Kandungan hadis dan Sunnah hanya sejalan dengan al-Qur'an bukan dengan ajaran-ajaran di luarnya. Bahkan, hadis atau Sunnah mempunyai fungsi yang sangat signifikan dalam menjelaskan kandungan ayat-ayat al-Qur'an, baik sebagai penjelas dan pemerinci kandungan al-Qur'an (bayan tafshil), pembatas makna ayat-ayat yang bersifat mutlak (bayan taqyid), pengkhusus makna ayat-ayat yan bersifat umum (bayan takhshish), memperkuat ketentuan-ketentuan al-Qur'an (bayan taqrir, taqyid, atau itsbat), penetap ketentuan yang tidak ditetapkan dalam al-Qur'an tetapi tidak bertentanan dengannya (bayan tasyri ), atau bahkan sebagai penghapus ketentuan yang terdapat dalam al-Qur'an (bayan nasakh). ${ }^{24}$

Demikian pula kedudukan Nabi dalam Islam adalah peletak hukum atau legislator (musyarri') berdasarkan wahyu Allah, bukan bertaklid kepada tradisi dan kebiasaan jahiliyah. Aturan-aturan syariat dalam Islam tidak sama dengan kebiasaan yang berlaku di Arab waktu itu. ${ }^{25}$

\section{Awal Pembentukan Hadis Nabi dalam Perspektif Joseph Schacht}

Schacht mengakui bahwa, penyelidikannya secara fundamental menggaris bawahi para pendahulunya, Goldziher dan Margoliouth, yang telah menyimpulkan konsep hadis dan Sunnah pada abad pertama dan pertengahan pertama kurun Islam. Ia berbeda dengan mereka hanya dalam menemukan, kapan permulaan hadis mulai didapati berlangsung, yang tidak berkaitan dengan Nabi melainkan berlangsung berkaitan denga para Tabi in (generasi setelah sahabat), kemudian pada berikutnya dengan para sahabat, dan akhirnya sesudah melewati suatu masa yang dikaitkan dengan Nabi Sendiri. ${ }^{26}$

Baik Ignaz maupun Joseph Schacht berpendapat bahwa, hadis tidaklah berasal dari Nabi melainkan sesuatu yang lahir pada abad pertama dan kedua Hijriyah. ${ }^{27}$

\footnotetext{
${ }^{24}$ Ibid., 105

${ }^{25}$ Ibid., 106

${ }^{26}$ Rahman, Islam..., 73

${ }^{27}$ Idri, Studi Hadis..., 317
} 
Pernyataaan lebih tegas lagi datang dari Joseph Schacht bahwa, tidak dapat ditemukan satupun hadis Nabi, terutama yang berkaitan dengan hukum, yang dapat dianggap sebagai hadis yang asli dari Nabi. ${ }^{28}$ Dalam bukunya An Introduction to Islamic Law, Joseph Schacht menyatakan:

"At an early period the ancient Arab idea of Sunna, precedent or normative custom, reasserted it self in Islam. The Arabs were and are bounded by tradition and precedent. Whatever was customary was right and proper, whatever the forfather had done deserved to be imitated. This was the golden rule of the Arabs whose existence on a narrow margin in an unpropitious environment did not leave the much room for experiment and innovation which might upset the precarious balance of heir lives. In this idea of precedent or sunna whole conservatism of the Arabs found expression." 29

Argumen Schacht mengenai jenis hadis ${ }^{30}$, yaitu dua bagian. Pertama berdasarkan kepada kenyataan yang dijumpainya dalam karya-karya Muhmmad ibn Idris al-Syafi' $i$ (150-204 H/767-819 M), dia menyimpulkan bahwa hadis-hadis Nabi sama sekali tidak ada hingga sekitar pertengahan abad ke 2 H/ 8 M. Pengalaman atau Sunnah sampai saat itu tidak memperhatikan Sunnah Nabi, melainkan sesuai dengan Sunnah masyarakat (walaupun Sunnah di Madinah umpamanya berbeda dengan di Irak), terutama karena merupakan hasil pendapat bebas para ahli kukum secara pribadi, dan akhirnya pertentangan alamiah para ahli hukum tehadap hadis nabi dipatahkan oleh usaha-usaha imam al-Syafi‘i, yang untuk pertama kalinya secara sistematik memperkenalkan konsep Sunnah Nabi ke dalam teori hukum Islam. Kedua, dengan membandingkan beberapa versi hadis permulaan dan yang kemudian, ia mendapatkan bahwa dalam periode Tabi in terdapat hadis yang tidak terdapat dalam periode yang terdahulu dan sejak itu kesemuanya dilupakan, atau bahwa versi Tabi in lebih lengkap daripada versi yang

\footnotetext{
${ }^{28}$ Ibid., 318

${ }^{29}$ Ibid.

${ }^{30}$ Pemikiran Schacht tentang hadis juga dikemukakan dalam bukunya yang berjudul "The Origins of Muhammadan Jurisprudence"yang sangat monumental bahkan disebut kitab suci kedua bagi Orientalis, dan bukunya yang berjudul "An Introduction to Islamic Law" yang terbit pada taun 1964. Melalui dua buku ini, Schach menkritik metode dan standar verifikasi keaslian hadis yang pertama kali disampaikan imam Syafi'i (767-82 M/ 15-204 H), dan yang kemudian dikembangkan oleh para murid imam Syafi' $i$ pada abad V>III dan IX, yang dikenal sebagai abad permulaan dalam pembentukan Islamic jurisprudence. Buku "The Origins of Muhammadan Jurisprudence" merupakan hasil karya Schacht yang dibangun di atas pemikiran tokoh-tokoh orientalis Eropa abad XIX dan XX yang memfokuskan kajiannya pada study of Islamic law, seperti Gustav Weil dan Ignaz Goldziher. Lihat: Setyawan, Studi Hadits..., 261
} 
terdahulu dan karena itu versi yang kemudian telah berkembang dengan jalan pemalsuan. $^{31}$

Dalam melakukan penelitiannya, khususnya terhadap hadis dan hukum Islam, Schacht menggunakan pendekatan sejarah dan sosiologi. Ini terlihat dari ungkapan Bernard Lewis yang mengatakan "Schacht approach was neither theological nor juristic, but rather historical and sociological". Dari sini terlihat bahwa dalam mengkaji penelitiannya, metode yang ditempuh Schacht dalam mengusung pemikirannya terhadap hadis dan hukum Islam adalah dengan menggunakan pendekatan sejarah dan sosiologi, bukan pendekatan teologi ataupun hukum. Tidak heran jika hasil kritik Schacht terhadap hadis lebih menggunakan analisis sejarah perkembangan Islam, khususnya pada abad kedua dan ketiga Hijriyah. ${ }^{32}$

Joseph Schacht dalam menerapkan teorinya selalu merujuk pada hadis-hadis hukum. Menurut Joseph Schacht, hadis hukum merupakan suatu bentuk inovasi yang muncul setelah beberapa pondasi Islam telah terbangun. Atau dengan kata lain kemunculan hadis hukum merupakan respon terhadap hukum-ukum yang sudah ada dalam masyarakat traisional waktu itu yang lebih berpegang pada living tradition. Dalam bahasan ini, teori backward projection atau projecting back kerap kali digunakan oleh Joseph Schacht untuk melacak penisbatan para ulama, kepada para sahabat sampai pada masa Rasulullah SAW. ${ }^{33}$

Ulama yang mengkritik dan menentang pernyataan-pernyataan Schacht di atas adalah Mustafa Azami. Teori Projecting back Schacht menurut Azami tidaklah logis. Hal ini disebabkan adanya fakta bahwa terdapat sejumlah riwayat yang sama dalam bentuk dan makna dalam literatur para ahli hadis (muhadditsun) klasik dari sekte-sekte yang berbeda. Seandainya hadis-hadis hukum dipalsukan pada abad kedua dan ketiga Hijriyah, niscaya tidak akan ada hadis yang dimuat bersama dalam sumber sekte-sekte yang bereda itu. Lebih jauh lagi, Azami mempertanyakan seandainya hadis betul-betul dibuat pada abad kedua dan ketiga Hijriyah, mengapa para ulama mau memilih dan mencantumkan orang-orang lemah untuk isnad mereka, sementara mereka sebenarnya

\footnotetext{
${ }^{31}$ Rahman, Islam..., 74

${ }^{32}$ Idri, Hadis dan Orientalis..., 182

${ }^{33}$ Wely Dozan, "Kajian Baru Kritik Hadits Joseph Schacht: Teori Analisis Teori Projecting Back”, Shopist, Vol. 1, No. 1 (Juni 2018), 99
} 
juga bisa dengan mudah memilih figur-figur yang lebih terhormat. Menurut Azami hal itu tidaklah logis. ${ }^{34}$

Sejarah menyatakan bahwa penulisan hadis sebenarnya sudah berlangsung jauh sebelum abad kedua dan ketiga Hijriyah, yakni saat Rasulullah di tengah-tengah sahabat. Penulisan Hadis tersebut berlangsung dalam bentuk catatan-catatan kecil $(\text { shahifah })^{35}$. Beberapa sahabat yang mempunyai catatan hadis adalah 'Ali ibn Abi Thalib (w. 40 H/611 M), Sumrah ibn Jundab (w. 60 H/680 H), 'Abd Allah ibn 'Amr ibn al-'Ash (w.65 H/685 M), 'Abd Allah ibn 'Abbas (w. 69 H/689 M), Jabir ibn 'Abd Allah al-Anshari (w. 78 H/697 M), 'Abd Allah ibn awfa' (w. 86 H). Catatan-catatan hadis ini di samping merupakan dokumen bahwa pada masa Nabi telah terjadi aktivitas penulisan hadis juga dapat digunakan sebagai sarana untuk periwayatan hadis secara tertulis. ${ }^{36}$

\section{Otentitas Sanad dan Matan Hadis Menurut Joseph Schacht}

Secara umum, kritik yang dilakukan oleh orientalis terhadap hadis disebabkan antara lain adanya kontroversi seputar penulisan hadis pada masa Nabi Saw. larangan penulisan hadis pada masa itu menurut orientalis menyebabkan kurangnya perhatian muhaddits, sehingga banyak hadis yang terlewatkan. Penulisan hadis yang dilakukan setelahnya menyisakan keraguan sehingga orientalis berkesimpulan bahwa tidak ada hadis yang benar-benar berkualitas shahih.

Faktor lain yang melatar belakangi kritik orientalis terhadap hadits adalah anggapan mereka yang menyatakan bahwa Sunnah atau hadis tidak lebih dari adat kebiasaan atau tradisi masyarakat Jahiliyyah yang diserap oleh agama Islam. ${ }^{37}$

Mereka juga beranggapan bahwa Sunnah bukanlah sumber tasyri‘. Menurut mereka, generasi awal Islam tidak pernah sekalipun mendasarkan keputusan hukum atau fatwa hukum kepada Sunnah. Tradisi penggunaan Sunnah baru muncul pada akhir abad ke II atau abad ke III Hijriyah. Pendapat ini juga diamini oleh Joseph Schacht. ${ }^{38}$

\footnotetext{
${ }^{34}$ Idri, Hadis dan Orientalis..., 192

${ }^{35}$ Ibid., 193

${ }^{36}$ Idri, Studi Hadis..., 38

${ }^{37}$ Hasan Suaidi, "Menyoal Kritik Sanad Joseph Schacht", Riwayah: Jurnal Studi Hadis, Vol. 2, No. 1 (2016), 92

${ }^{38}$ Ibid., 93
} 
Rancang bangun terbentuknya sanad adalah temasuk dari tema pokok kajian orientalis, yang dari sudut inilah, kelemahan-kelemahan hadis dalam perspektif orientalis kemudian dibeberkan. ${ }^{39}$

Riset Schacht terhadap hadis agak berbeda dengan para pengkaji hadis pada umumnya. Lazimnya riset hadis menyoal dua aspek utama yang menyusun hadis, yakni matan dan sanad. Dalam praktik risetnya, Schacht justru lebih banyak menyoroti aspek sanad daripada matan (redaksi) hadis. ${ }^{40}$

Menurut pengakuannya, Prof. Schacht telah mempelajari hadis-hadis yang berkaitan dengan masalah fiqih serta perkembangannya. Ia berpendapat bahwa isnad adalah bagian dari tindakan sewenang-wenang dalam hadis nabi SAW.. Hadis itu sendiri dikembangkan oleh kelompok-kelompok yang berbeda-beda yang ingin mengaitkan teorinya kepada tokoh-tokoh terdahulu. ${ }^{41}$

Menurut Prof. Schatcht, Sanad-sanad hadis itu sebagian besar adalah palsu, dan hal itu diketahui oleh semua orang bahwa sanad-sanad itu pemakaiannya dimulai dalam bentuk yang sangat sederhana, kemudian berkembang dan mencapai bentuknya yang sempurna pada paruh kedua abad ketiga Hijriyah, kebanyakan sanad-sanad itu tidak mendapatkan perhatian yang cukup. Apabila ada suatu kelompok yang ingin mengaitkan (menisbatkan) pendapatnya dengan orang terdahulu, maka kelompok tersebut akan memilih tokoh-tokoh orang-orang dahulu itu dan menaruhnya dalam sanad. ${ }^{, 42}$ Dia menyatakan bahwa sanad merupakan hasil rekayasa para ulama abad kedua Hijriyah dalam menyandarkan sebuah hadis kepada tokoh-tokoh terdahulu hingga akhirnya sampai kepada Nabi untuk mencari legitimasi yang kuat tehadap hadis tersebut. $^{43}$

Gugatan Schacht terhadap hadis berkisar pada masalah isnad dan persoalan umur atau penanggalanya. ${ }^{44}$ Studi Schacht, diawali dengan meneliti proses kemunculan hukum Islam (fikih). Berdasarkan hasil penelitiannya, ia berkesimpulan bahwa hukum Islam belum ada sampai pada masa al-Sha'bi (w.110 H). Penegasan ini memberikan

\footnotetext{
${ }^{39}$ Muhammad Sholikhin, Hadis Asli Hadis Palsu (t.t: Garudhawaca, t.tp), 74

${ }^{40}$ Muksin, al-Hadits dalam Pandangan..., 117

${ }^{41}$ M. Azami, Hadis Nabawi dan Sejarah Kodifikasinya, terj. Ali Mustafa Yaqub (Jakarta: Pustaka Firdaus, 2014), 534

${ }^{42}$ Ibid., 564

${ }^{43}$ Idri, Studi Hadis..., 314

${ }^{44}$ Syamsuddin Arief, Orientalis dan Diabolisme Pemikiran (Jakarta: Gema Insani, 2008), 33
} 
pengertian bahwa apabila diketemukan hadis yang berkaiatan dengan hukum Islam, maka hadis-hadis tersebut adalah buatan atau ciptaan orang-orang yang hidup sesudah al-Sha'bi. Schacht beranggapan bahwa hukum Islam baru dikenal sejak masa pengangkatan qadhi (hakim agama). Sedangkan pada masa khalifah, tidak pernah terjadi pengangkatan qadhi, karena hal itu baru dilaksanakan pada masa dinasti Umayyah. ${ }^{45}$

Teori ini berawal dari pemahaman Schacht terhadap perkembangan hadis sejalan dengan perkembangan hukum Islam. Menurutnya, hukum Islam baru dikenal sejak pengangkatan para qadhi pada masa Dinasti Umayyah. Sekitar akhir abad pertama Hijriyah, pengangkatan para qadhi ditujukan kepada para fuqaha' yang jumlahnya kian bertambah sehingga akhirnya menjadi aliran fiqh klasik (madzhab). Untuk memperoleh legitimasi yang kuat tehadap putusan hukum yang diambil, maka para qadhi menyandarkan putusan-putusan itu kepada tokoh-tokoh yang sebelumnya dipandang mempunyai otoritas. Penyandaran ini tidak hanya sampai kepada generasi di atas mereka, tetapi sampai kepada para sahabat dan akhirnya sampai kepada Nabi. Tindakan ini melahirkan kelompok oposisi yang terdiri dari para ahli hadis. Pokok pikiran para ahli hadis ini adalah bahwa hadis-hadis yang disertai dengan sanad yang mereka sandarkan kepada tokoh-tokoh sebelum mereka hingga akhirnya juga bermuara kepada Nabi. ${ }^{46}$

Pandangan Schacht tersebut bertumpu pada pandangan pendahulunya, Goldziher yang menyebut bahwa kegiatan kodifikasi hadis sampai masa al-Bukhari (w. 256 H/870 M) serta enam imam hadis berikutnya, tidak lebih sekedar kegiatan pembuatan tafsir hadis, yang jika sudah diakui secara kanonik, akan ditingkatkan derajatnya sejajar sebagai sumber yang menentukan, yang berhak disandarkan sebagai Sunnah Nabi. Sedangkan para pencipta hadis, menurut Goldziher, umumnya terdiri dari orang-orang yang berpura-pura saleh, untuk mendapatkan kedudukan dihadapan kaum muslimin.

Menurut kesimpulan Schacht, keputusan-keputusn yang dimunculkan oleh para qadhi itu memerlukan legitimasi dari orang yang memiliki otoritas lebih tinggi. Karenanya, mereka tidak menisbahkannya kepada dirinya sendiri, melainkan menisbahkannya kepada tokoh-tokoh sebelum mereka sendiri, misalnya orang-orang

\footnotetext{
${ }^{45}$ Sholikhin, Hadis Asli..., 76

${ }^{46}$ Idri, Studi Hadis..., 314
} 
Irak menisbahkan pendapatnya kepada Ibrahim al-Nakha'i, dan sebagainya. Pada perkembangan selanjutnya, supaya mendapat legitimasi lebih kuat lagi, pendapat para qadhi itu dinisbahkan kepada para sahabat dan kemudian kepada Nabi. Inilah rekonstruksi terbentuknya sanad menurut Schacht, yakni dengan melakukan rancang bangun ke belakang (The Projecting Back). ${ }^{47}$ Gejala umum yang terdapat dalam sanad hadis adalah semakin jauh orang-orang dari masa Nabi SAW., semakin bertambah pula jumlah orang-orang yang meriwayatkan (rawi) hadis Nabi SAW. ${ }^{48}$

Artinya bahwa sebenarnya pada mulanya tidak ada sistem sanad, namun kemudian sengaja dibuatkan isnad, sehingga isnad tidak memiliki nilai historis sama sekali. Schacht menyatakan bahwa sanad adalah bukti tindakan sewenang-wenang dan kecerobohan yang dilakukan oleh para ulama Islam pada saat itu. Hal ini dikarenakan, hadis pada awalnya hanya hasil penalaran perseorangan, yang ditempatkan dibawah perlindungan para sahabat, lalu disiarkan kepada publik atas nama Nabi. Hadis, dalam teori Schacht hanyalah pengembangan oleh kelompok-kelompok yang berbeda pendapat dalam masyarakat Islam yang ingin mengaitkan teorinya kepada tokoh-tokoh terdahulu. ${ }^{49}$

Setuju dengan pendapat Schacht, Juynboll menuduh perawi yang dinamakan "commont link" ${ }^{50}$ sebagai orang yang pertama kali memalsukan suatu hadis, bahwa hadis yang diriwayatkan olehnya, sebenarnya bukan barasal dari NabiSAW., akan tetapi perkataannya sendiri atau perkataan orang lain yang disandarkan kepada Nabi SAW. ${ }^{51}$

Kritik terhadap metode dan teori yang dikembangkan oleh Joseph Schacht dalam kajian sanad hadis juga dilakukan oleh beberapa sarjana muslim, antara lain oleh MM. Azami. Persoalan pertama yang dikritik oleh MM. Azami terhadap Joseph Schacht

\footnotetext{
${ }^{47}$ Sholikhin, Hadis Asli..., 76- 77

${ }^{48}$ Azami, Hadis Nabawi..., 548

${ }^{49}$ Sholikhin, Hadis Asli..., $77-78$

${ }^{50}$ Common link adalah istilah yang dipakai untuk seorang periwayat hadis yang mendengarkan suatu hadis dari seorang yang berwenang, lalu mengajarkannya kepada sejumlah murid yang pada gilirannya kebanyakan dari mereka mengajarkannya kembali kepada dua atau lebih dari muridnya. Keberadaan Common link (tokoh penghubung/common transmitter) dalam rantai periwayatan mengindikasikan bahwa hadis itu berasal dari masa tokoh tersebut. Dengan kata lain, Common link adalah periwayat tertua yang disebut dalam bundel isnad yang meneruskan hadis kepada lebih dari satu murid. Dengan demikian, ketika bundel isnad itu mulai menyebar untuk pertama kalinya, di sanalah ditemukan Common link-nya. Teori ini berangkat dari asumsi bahwa semakin banyak jalur periwayatan yang bertemu pada seorang rawi (periwayat hadis), maka semakin besar pula jalur periwayatan tersebut mempunyai klaim kesejarahan atau sahih. Lihat: Setyawan, Studi Hadits..., 263-264.

${ }^{51}$ Arief, Orientalis dan Diabolisme..., 35
} 
adalah tentang objek kitab kajiannya. MM. Azami berpandangan bahwa pemilihan kitab-kitab dalam kajian sanad yang dilakukan oleh Schacht antara lain kitab Muwaththa', karya Imam Malik, Muwaththa' karya Imam Muhammad al-Syaibani dan al-Umm karya Iam Syafi'i adalah kurang tepat. Hal itu karena kitab-kitab tersebut lebih tepat disebut dengan kitab fiqh, bukan kitab hadis. Namun demikian, Schacht menggeneralisasikan hasil kajiannya dan menerapkan hasil kajiannya terhadap kitabkitab hadis. padahal menurut Azami, karakteristik kitab-kitab fiqh dan hadis berbeda. Selain Azami, Muhammad Bahauddin juga mengkritik pilihan Schacht terhadap kitab fiqh dalam kajian hadis. Bahauddin berpendapat bahwa perhatian terhadap sanad merupakan wilayah para ulama hadis bukan ulama $f i q h{ }^{52}$

Mushthafa Azami membantah tuduhan Schacht yang menyatakan bahwa sanad dan matan hadis adalah rekayasa umat Islam pada abad kedua Hijriyah, berikut penjelasannya ${ }^{53}$ :

1. Kenyataan sejarah membuktikan bahwa permulaan pemakain sanad adalah sejak masa Nabi, seperti anjurannya kepada para sahabat yang menghadiri majelis Nabi untuk menyampaikan hadis kepada yang tidak hadir.

2. Mayoritas pemalsuan hadis tejadi pada tahun keempat puluh Hijriyah, yang dipicu oleh persoalan politik, karena diantara umat Islam saat itu ada yang lemah keimanannya sehingga membuat hadis untuk kepentingan faksi politik atau golongan mereka.

3. Objek penelitian para orientalis di bidang sanad tidak dapat diterima, karena yang mereka teliti bukan kitab-kitab hadis melainkan kitab-kitab fikih dan sirah.

4. Teori Projecting Back yang dijadikan dasar argumentasi beserta contoh-contoh hadis yang dijadikan sampel, karenanya menjadi gugur dengan banyaknya jalan periwayatan suatu hadis.

5. Tidak pernah terjadi perkembangan dan perbaikan terhadap sanad seperti membuat marfu' hadis yang mawquf, atau menjadikan muttashil hadis yang mursal.

6. Penelitian dan kritik ulama hadis atas sanad dan matan hadis, dengan segala kemampuan mereka, dilakukan atas dasar keikhlasan dan tanpa tendensi duniawi.

\footnotetext{
${ }^{52}$ Suadi, Menyoal Kritik..., 101

${ }^{53}$ Idri, Studi Hadis..., 321
} 


\section{E. Pandangan Joseph Schacht terhadap Kehujjahan Hadis}

Kehujjahan hadis dapat diketahui melalui argumentasi rasional dan teologis sekalipun. Beriman kepada Rasulullah merupakan salah satu rukun iman yang harus diyakini oleh setiap Muslim. Keimanan ini diperintahkan oleh Allah dalam al-Qur'an agar manusia beriman dan mentaati Nabi. ${ }^{54}$ Menerima hadis sebagai hujjah merupakan bagian yang tak terpisahkan dari keimanan seseorang. Apabila ia tidak menerima hadis sebagai hujjah, maka sama halnya ia tidak beriman kepada Rasulullah. ${ }^{55}$

Pada dasarnya Sunnah Nabi berfungsi menjelaskan hukum-hukum dalam alQur'an dalam segala bentuknya. Allah SWT. menetapkan hukum dalam al-Qur'an untuk diamalkan, karena dalam pengamalan itulah terletak tujuan yang digariskan. Tetapi pengamalan hukum Allah itu dalam bentuk tertentu tidak akan terlaksana menurut apa adanya sebelum diberi penjelasan oleh Nabi. Dengan demikian, penjelasan Nabi itu bertujuan supaya hukum-hukum yang ditetapkan Allah dalam al-Qur'an secara sempurna dapat dilaksanakan oleh umat. ${ }^{56}$

Banyak ayat al-Qur'an dan Hadis yang menjelaskan bahwa hadis merupakan salah satu sumber hukum Islam selain al-Qur'an yang wajib diikuti sebagaimana mengikuti al-Qur'an, baik dalam bentuk awamir maupun nawahi-nya. ${ }^{57}$

Pandangan orientalis terhadap hadis sebagai sumber hukum dapat ditelusuri dari pandangan mereka tentang peranan Nabi Muhammad dalam pembentukan hukum. ${ }^{58}$ Menurut Schacht, tujuan Muhammad selaku Nabi bukanlah untuk membuat sistem hukum yang baru, tetapi sekedar mengajarkan manusia bagaimana harus bertindak agar selamat menghadapi perhitungan pada hari pemabalasan dan agar masuk surga. ${ }^{59}$

Schacht berkata, "Pada waktu Nabi di Madinah, ia menjadi Nabi sekaligus pembuat hukum, padahal kekuasaannya tidak mencakup segi-segi penetapan hukum. Kekuasaan Nabi SAW. untuk orang-orang mu'min hanyalah dalam masalah keagamaan saja, sedang untuk orang-orang munafik hanya dalam masalah politik saja". ${ }^{60}$

\footnotetext{
${ }^{54}$ Idri, Studi Hadis..., 20

${ }^{55}$ Ibid.

${ }^{56}$ Amir Syarifuddin, Ushul Fiqh (Jakarta: Kencana, 2009), 103

${ }^{57}$ Mudasir, Ilmu Hadis (Bandung: Pustaka Setia, 2008), 66

${ }^{58}$ Idri, Studi Hadis..., 319

${ }^{59}$ Ibid.

${ }^{60}$ Azami, Hadis Nabawi..., 588
} 
Seandainya Schacht mau merujuk al-Qur'an, tentu ia akan mendapatkan ajaranajaran yang menggambarkan kekuasaan Nabi SAW. secara jelas. ${ }^{61}$ Sebagaimana penjelasan yang terdapat dalam Firman Allah sebagai berikut:

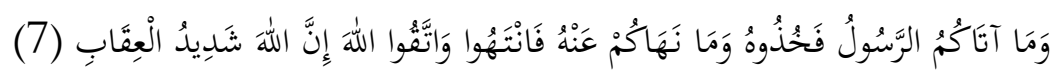

Apa yang diberikan oleh Rasul kepadamu, maka ambillah hal itu, dan apa yang dilarangnya bagimu, maka tinggalkanlah. ${ }^{62}$

Di samping itu, undang-undang tertulis yang tertua, yaitu undang-undang Madinah (Dustur al-Madinah) menyebutkan bahwa Nabi SAW. mempunyai kekuasaan tertinggi untuk menyelesaikan masalah (mengadili perkara), yaitu dalam kalimat yang berbunyi: "Dan sesungguhnya kalian apabila berselisih pendapat dalam suatu masalah, maka kembalikanlah penyelesaiannya kepada Allah dan Muhammad". ${ }^{63}$ Hal ini sejalan dengan Firman Allah dalam al-Qur'an sebagi berikut:

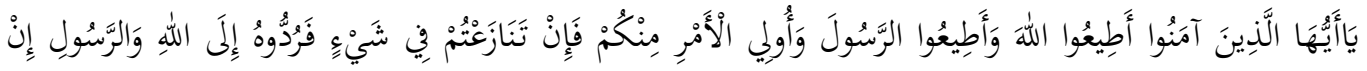

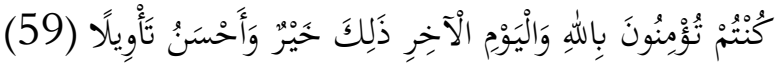

Wahai orang-orang yang beriman, taatlah kepada Allah, dan taatlah kepada Rasul(Nya), dan ulil amri di antara kamu. Kemudian jika kamu berlainan pendapat dalam suatu masalah, maka kembalikanlah hal itu kepada Allah (al-Qur'an) dan Rasul (Sunnahnya), jika kamu benar-benar beriman kepada Allah dan hari kemudian. Yang demikian itu adalah lebih utama (bagimu) dan sebaik-baik pengembalian. ${ }^{64}$

Selain memerintahkan umat Islam agar percaya kepada Rasulullah Saw., Allah juga menyerukan agar umat-Nya menaati segala bentuk perundang-undangan dan peraturan yang dibawanya, baik berupa perintah maupun larangan. Tuntutan taat dan patuh kepada Rasulullah Saw. ini sama halnya dengan tuntutan taat dan patuh kepada Allah SWT. ${ }^{65}$

\footnotetext{
${ }^{61}$ Ibid., 585-588

${ }^{62}$ Al-Qur'an, 59: 7.

${ }^{63}$ Azami, Hadis Nabawi..., 589

${ }^{64}$ Al-Qur'an, 4: 59

${ }^{65}$ Mudasir, Ilmu Hadis..., 68
} 
Rasulullah juga mempunyai kekuasaan tertinggi dalam menentukan dan melaksanakan hukum. ${ }^{66}$ Menegakkan keadilan merupakan kewajiban pokok bagi Nabi dan para Khalifah sesudahnya. Syari’ah Islam adalah samawi (bersumber dari Wahyu), begitu pula menegakkan keadilan adalah sesuatu yang bersumber dari Allah, dan mencontoh Nabi SAW. adalah merupakan suatu kewajiban yang harus diikuti oleh ummat Islam. ${ }^{67}$

Banyak peristiwa yang menunjukkan adanya pengunaan Sunnah sebagai sumber hukum Islam, antara lain sebagai berikut ${ }^{68}$ :

1. Ketika Abu bakar dibai'at menjadi khalifah, ia pernah berkata, "saya tidak meninnggalkan sedikitpun sesuatu yang diamalkan oleh Rasululla Saw., sunguh saya takut tersesat jika meninggalkan perintahnya".

2. Pada saat Umar berada di depan Hajar Aswad ia berkata: "saya tau bahwa engkau adalah batu. Seandainya saya tidak melihat Rasululla Saw. menciummu, saya tidak akan menciumnya”.

3. Pernah ditanyakan kepada 'Abdullah ibn 'Umar tentang ketentuan safar dalam alQur'an. Ibnu 'Umar menjawab: “Allah Swt telah menutus Nabi Muhammad Saw. kepada kita, dan kita tidak menetahui sesuatu. Maka sesunggunya kami berbuat sebagaimana Rasulullah Saw. berbuat".

4. Diceritakan dari Sa'id ibn al-Musayyab bahwa 'Utsman ibn 'Affan berkata: "saya duduk sebagaimana duduknya Rasulullah Saw., saya makan sebagaimana makannya Rasulullah Saw., dan saya salat sebagaimana salatnya Rasulullah SAW".

Al-Quran dan hadis sebagai pedoman hidup, sumber hukum dan ajaran Islam yang tidak dapat dipisahkan antara satu dan lainnya. al-Qur'an sebagai sumber pertama memuat ajaran-ajaran yang bersifat umum dan global, sedangkan hadis sebagai sumber ajaran kedua tampil untuk menjelaskan keumuman isi al-Qur'an tersebut. ${ }^{69}$

\footnotetext{
${ }^{66}$ Azami, Hadis Nabawi..., 589

${ }^{67}$ Ibid., 593

${ }^{68}$ Sulidar, "Urgensi Kedudukan Hadis terhadap Alquran dan Kehujjahannya dalam ajaran Islam", Analytica Islamica, Vol. 2, No. 2 (2013), 340

${ }^{69}$ Mudasir, Ilmu Hadis..., 75
} 


\section{F. Kesimpulan}

Pandangan Schacht terhadap Sunnah sangat berbeda dengan ulama hadis. Schacht menganggap Sunnah merupakan konsep bahasa Arab kuno yang berlaku kembali sabagai salah satu pusat pemikiran Islam. Sunnah Nabi dianngap sebagai tradisi Arab kuno yang kembali mengemuka dalam ajaran Islam. Jadi, secara tidak langsung ia menyatakan bahwa, Sunnah bukan berasal Nabi, dan yang dianggap Sunnah adalah tradisi yang diadopsi dari zaman pra Islam.

Klaim tersebut tidak bisa diterima oleh ulama hadis karena Sunnah dan hadis memang benar-benar berasal dari Rasulullah bukan dari luar Islam. Hal ini dapat dilihat pada kandungan hadis dan Sunnah yang tidak sama dengan kandungan dalam kitab lain. Hadis dan Sunnah hanya sejalan dengan ajaran al-Qur'an, dan kedudukan Nabi dalam Islam sebagai peletak hukum berdasarkan wahyu Allah, bukan bertaklid kepada tradisi dan kebiasaan di masa jahiliyah.

Menurut Schacht, Hadis baru terbentuk pada abad kedua Hijriyyah, dan sanad juga merupakan hasil rekayasa para ulama untuk mendapatkan legitimasi yang kuat tehadap hadis. Sebenarnya penulisan hadis sudah berlangsung jauh sebelum abad kedua dan ketiga Hijriyah, yakni saat Rasulullah di tengah-tengah sahabat. Beberapa sahabat yang mempunyai catatan hadis adalah 'Ali ibn Abi Thalib (w. 40 H/611 M) dan 'Abd Allah ibn 'Amr ibn al-'Ash (w.65 H/685 M).

Schacht menganggap bahwa, Nabi tidak mempunyai kekuasaan dalam penetapan hukum, secara otomatis Sunnah atau hadis Nabi dianggap tidak berfungsi sebagai sumber hukum Islam, padahal dalam al-Qur'an dengan jelas Allah memerintahkan kepada umat Islam untuk mentaati Allah dan Rasulnya, dan menerima ketetapan yang telah dibuatnya.

\section{Daftar Pustaka}

Amir Syarifuddin, Amir. Ushul Fiqh. Jakarta: Kencana, 2009.

Arief, Syamsuddin. Orientalis dan Diabolisme Pemikiran. Jakarta: Gema Insani, 2008.

Azami, M. Hadis Nabawi dan Sejarah Kodifikasinya, terj. Ali Mustafa Yaqub. Jakarta: Pustaka Firdaus, 2014. 
Badawi, Abdurrahman. Ensiklopedi Tokoh Orientalis, tej. Amroeni Drajat. Yogyakarta: LkiS Yogyakarta, 2003.

Dozan, Wely. Kajian Baru Kritik Hadits Joseph Schact: Teori Analisis Teori Projecting Back. Shopist. Vol. 1, No. 1. Juni 2018.

Idri. Hadis dan Orientalis Perspektif Ulama Hadis dan Para Orientalis tentang Hadis. Depok: Kencana, 2017. Studi Hadis. Jakarta: Kencana, 2010.

Minhaji, Akhmad. Kontroversi Pembentukan Hukum Islam, terj. Ali Masrur. Yogyakarta: UII Pres, 2001.

Mudasir. Ilmu Hadis. Bandung: Pustaka Setia, 2008.

Muksin, Ucin. al-Hadits dalam Pandangan Orientalis (Joseph Schacht). Ilmu Dakwah: Academic Journal for Homiletic Studies. Vol. 4, No.11. Januari-Juni 2008.

Rahman, Fazlur. Islam, terj. Shonhadji. Jakarta: Bumi Aksara, 1992.

Rhaien, Ainur. Otentitas Hadits; Studi Kritik Pemikiran Josepht Schacht, dalam Antologi Kajian Islam, ed. Husein Aziz, et.al. (Surabaya: Pascasarjana UIN Sunan Ampel Surabaya, 2015)

Setyawan, Cahya Edi. Studi Hadits:Analisis Terhadap Pemikiran Schacht dan A 'zami. Jurnal Kajian Islam Interdisipliner. Vol.1, No. 2. Desember 2016.

Sholikhin, Muhammad. Hadis Asli Hadis Palsu. t.t: Garudhawaca, t.tp.

Suadi, Hasan. Menyoal Kritik Sanad Joseph Schacht. Riwayah: Jurnal Studi Hadis. Vol. 2, No. 1. 2016.

Sulidar. Urgensi Kedudukan Hadis terhadap Alquran dan Kehujjahannya dalam ajaran Islam. Analytica Islamica. Vol. 2, No. 2. 2013. 